Check for updates

The BMJ

Cite this as: BMJ 2021;374:n2291 http://dx.doi.org/10.1136/bmj.n2291 Published: 27 September 2021

\section{Covid-19: England sees biggest fall in life expectancy since records began in wake of pandemic}

Gareth lacobucci

The covid-19 pandemic led to the biggest year-on-year drop in life expectancy in England since statistics were first collected in 1981, Public Health England has said.

In 2020, the agency said that "the very high level" of excess deaths because of the pandemic caused life expectancy in England to fall 1.3 years for men to 78.7 and 0.9 years for women to 82.7. This was the lowest life expectancy in England for both sexes since 2011.

Not all countries have reported life expectancy data for 2020 yet. But of those that have, PHE noted that Italy, Poland, and Spain experienced similar decreases in life expectancy to England in 2020, while France had a smaller decrease. Germany had little or no relative excess mortality in men or women. The US and Poland had the highest relative excess mortality in 2020 , in both men and women.

The data were presented in PHE’s Health Profile for England 2021 report, ${ }^{1}$ published on 15 September.

In England, covid-19 was the leading underlying cause of death among men in 2020, replacing heart disease, and the second largest cause of death among women, after dementia and Alzheimer's disease. Dementia was also reported as the main pre-existing condition on $25.6 \%$ of deaths certificates involving covid-19, the report added.

Deaths linked to alcohol use increased by around 20\% between 2019 and 2020, which PHE described as "a significant acceleration in the upward trend" seen before the pandemic.

The data also show that the level of health inequalities in life expectancy was larger last year than at any point in the past two decades. The gap in male life expectancy between the most and least deprived areas in England was 10.3 years in 2020, one year larger than in 2019. The gap for women was 8.3 years in 2020, 0.6 years larger than in 2019.

"This demonstrates that the pandemic has exacerbated existing inequalities in life expectancy by deprivation," PHE said.

Covid-19 was the cause of death that contributed most to the inequality gap in 2020, but PHE said that higher mortality from heart disease, lung cancer, and chronic lower respiratory diseases in deprived areas "remained important contributors."

PHE concluded, "The report has highlighted how the direct impact of the pandemic has disproportionally affected people from ethnic minority groups, people living in deprived areas, older people and those with pre-existing health conditions.”

It added, "There have been substantial indirect effects on children's education and mental health, and on employment opportunities across the life course, but particularly for younger people working in sectors such as hospitality and entertainment. In addition, it is clear that access and use of a range of health services has been disrupted during the pandemic and the long term effects of this is not yet realised."

1 Public Health England. Health Profile for England 2021. https://fingertips.phe.org.uk/static-reports/health-profile-for-england/hpfe_report.html.

This article is made freely available for use in accordance with BMJ's website terms and conditions for the duration of the covid-19 pandemic or until otherwise determined by BMJ. You may use, download and print the article for any lawful, non-commercial purpose (including text and data mining) provided that all copyright notices and trade marks are retained. 